\title{
Grotesco desejo: Erotismo, monstruosidade e internet desde a animação pornô
}

\author{
Grotesque desire: \\ Eroticism, monstrosity and internet since porn animation
}

Alexandre Eustáquio Teixeira ${ }^{1}$

\begin{abstract}
Resumo: No contexto das dinâmicas contemporâneas do erotismo, a pornografia produzida, distribuída e consumida a partir da internet ocupa um lugar central na produção de certa socialidade erótica. Ainda nesse contexto, surgem produtos que deslocam e suspendem sentidos e significados para as representações sobre o sexo, entre elas a animação. A partir de uma pesquisa desenvolvida a partir de acervos imagéticos em sites de compartilhamento de conteúdo pornográfico o presente artigo discute os processos de pornonificação de corpos conceituáveis como abjetos pela ausência de atributos humanos em sua constituição: os monstros. No texto sinalizamos para as zonas de convergência e encontro que produzem esses corpos a partir de uma dupla posição entre alteridades e excitação a partir de recursos técnicos e narrativos específicos.

Palavras-chave: animação pornográfica; representação; monstruosidade; dispositivo da sexualidade; socialidades mediadas na internet.
\end{abstract}

\footnotetext{
${ }^{1}$ Professor adjunto IV do Departamento de Ciências Sociais da PUC Minas. Doutor e Mestre em Ciências Sociais pela PUC Minas. E-mail: aeteixeira@hotmail.com
} 


\title{
Grotesco desejo: Erotismo, monstruosidade e internet desde a animação pornô
}

\begin{abstract}
In the context of the contemporary dynamics of eroticism, pornography produced, distributed and consumed from the internet occupies a central place in the production of certain erotic sociality. Indeed, there are products that move and suspend meanings for the representations about sex, as animation. From a research developed from imagery collections in sites of pornographic content sharing, this article discusses the pornification processes of bodies conceptualized as abject by its absence of human attributes in their constitution: the monsters. In the text, we signal to the zones of convergence and encounter that produce these bodies from a double position between alterities and excitation from specific technical and narratives resources.
\end{abstract}

Keywords: Porn animation. Representation. Monstrosity. Sexuality dispositive. Internet mediated socialities.

\section{Introdução}

Este trabalho é um recorte de um projeto mais amplo que teve como propósito central analisar as imagens e representações do monstro no contexto da animação pornográfica, um segmento ou nicho da indústria de produção de material audiovisual pornográfico que tem crescido significativamente nas últimas décadas com a sofisticação dos equipamentos e dispositivos digitais, e pela difusão e popularização da internet a partir dos principais centros econômicos e tecnológicos do capitalismo global. Como recorte específico, a partir de uma imersão em um campo de fronteira entre estudos sobre socialidades produzidas a partir da internet, pornografia e erotismos, o presente artigo discute os processos de "pornificação", ou seja, do investimento de um invólucro erótico e de excitação sobre certos corpos e seres que a princípio estão apartados de processos desejantes, no presente 
caso, a própria noção de "monstruosidade" como atributo do ficcional.

Definir o que é animação não é tarefa simples, pois como já observou Pilling (citada por CRUZ, 2006), trata-se de uma mídia abrangente que utiliza diferentes tipos de técnicas e materiais para a sua produção. Pode ser originada a partir da atribuição ou dotação de movimento para diferentes objetos: desenhos feitos à mão, imagens digitais, bonecos de massa, pinturas, estátuas, etc. Também pode ser produzida para diferentes finalidades: artísticas, comerciais, experimentais, lúdicas, publicitárias ou documentais. As animações pornográficas que foram analisados neste trabalho se referem a um conjunto de produções específicas, derivadas de imagens produzidas e animadas digitalmente, originalmente para fins comerciais, e que são disponibilizadas na rede mundial de computadores para serem consumidas em desktops, tablets, notebooks ou smartphones a ela conectados por cabos ou redes sem fio.

Já o pornô, como um produto de mercado, como afirma Diaz-Benítez (2010) é um tipo de produto específico produzido para atender a ideologias sobre o sexo e a demandas de consumo. Efeito desses cruzamentos é que a produção pornográfica pode ser lida como refratária de práticas e condutas tomadas como superfície de representação de ideias, práticas e convenções sobre poder, gênero, sexualidades, intimidades, constituições corporais, marcadores e performances de prestígio (cf. PINHO, 2012).

Nesse contexto, a animação pornográfica se caracteriza simultaneamente como um espaço de síntese e disjunção na relação entre indústria pornográfica e sociedade. É um nicho dotado de especificidades e relações de continuidade com o espectro amplo da produção pornográfica, possibilitando distensões e divergências, invenção e reiteração de convenções. Em seu aspecto técnico, a animação pornográfica permite 
Grotesco desejo: Erotismo, monstruosidade e internet desde a animação pornô

potencializar a ambivalência da cena pornográfica como duplamente realista e espetacular (DÍAZ-BENÍTEZ, 2010, p. 99), ao mesmo tempo em que permite a constituição de repertórios narrativos e estéticos alternativos a partir da criação de corporalidades não humanas e modos de interação e relação impossíveis à produção fílmicas com pretensões "realistas".

\section{Pornografia, animação e regimes de criatividade}

Em um cenário onde a indústria pornográfica é constituída por agentes com possibilidades de circulação e capitalização diversas (desde grandes produtoras, passando por prestadores de serviços para essas grandes empresas, até produtores autônomos), a animação pornográfica também pode ser caracterizada pelas estratégias através das quais os materiais são produzidos e veiculados por meio da apropriação, por agentes não diretamente vinculados à indústria pornográfica, de ferramentas e espaços criados para outros fins, como, por exemplo, jogos digitais desenvolvidos para computador, que podem ser jogados offline ou online, como os populares "eroges" - jogos pornográficos com estética de animês, muito comuns no Japão. A despeito dos altos custos que envolvem a produção das animações, também se particulariza pelo uso criativo das ferramentas para simulação de situações não convencionais, dotadas de elementos fantasiosos e fantásticos em estreito diálogo com convenções e expectativas que se produzem a partir de certos arranjos e expectativas. Essas configurações iniciais são potencialmente postas em fluxo a partir das possibilidades oriundas da conectividade através da internet $\mathrm{e}$ das mídias sociais móveis, que permitem o acesso a qualquer um dotado dos recursos técnicos e informacionais mínimos necessários.

O interesse aqui recai não nos processos de "produção" e "consumo" desse conteúdo, mas de maneira mais detida, à 
sua instância representacional. Em última instância, se concordamos com Wagner (1972) que o processo de significação humano é um processo de produção e atualização de metáforas que, no contexto ocidental ao menos, têm a possibilidade de se estender a domínios mais amplos, a hipótese é que analisar esses sujeitos da ficção pode oferecer contribuir para a compreensão de dinâmicas que ultrapassam o próprio campo da ficcionalidade da animação enquanto produto cultural. $\mathrm{O}$ interesse é discutir a extensão de representações sobre o erotismo contemporâneo e desejos destoantes no contexto desse espaço de nicho específico que é a animação pornográfica. Sendo assim, analisando o ímpeto com que a sofisticação dos recursos tecnológicos tem embaralhado ideias e estéticas sobre real e espetacular, o eixo de análise que interessa aqui recai sobre os agentes que destoam dessa dimensão realista, ainda que em estreito diálogo com alguns aspectos dela, como se verá: os "monstros".

Um empreendimento desse tipo inevitavelmente encontra como primeiro impasse a conceituação sobre os marcadores que norteiam essa discussão. Monstros, freaks, esquisitices, anormalidades são categorias que escorregam e se multiplicam em profusão e intensidade no contexto Ocidental, sinalizando movimentos semânticos que se encontram também com valorações morais, concepções sociais e culturais sobre o funcionamento e ordenamento da dinâmica entre grupos e pessoas e até mesmo dispositivos ontológicos que atribuem posições, funções, sentidos e domínios para a ação de uma miríade muito ampla de seres concebíveis como humanos ou não-humanos. A questão central e articuladora, no entanto, permanece. Afinal de contas, o que queremos dizer quando falamos em monstros, monstruosidade?

Segundo Jean-Jacques Courtine (2010), o monstro se refere a uma entidade que apresenta um corpo e/ou comportamento que ultrapassa o que é considerado normal - 
normal aqui assume o status de sinônimo para humano -, e por isso mesmo, apresenta-se, ao mesmo tempo, como algo fascinante, ameaçador, incrível, impossível e transgressivo. Trata-se de uma "aparição do inumano, da negação do ser humano no espetáculo do ser humano vivo" (COURTINE, 2010, p. 498). Já o monstruoso se refere à construção simbólica e discursiva sobre os monstros, é o "universo de imagens e de palavras que supostamente transcreve o irrepresentável (...) a substituição dos monstros reais pelos monstros virtuais concebidos num universo de sinais" (COURTINE, 2010, p.498499), ou mais, uma construção sistemática de objetos de consumo e de circulação sobre essas entidades.

Neste trabalho utilizo os termos pornografia e erotismo como sinônimos, já que não seria possível definir, de forma objetiva e universal, as suas diferenças (GREGORI, 2012) Apesar de certa tradição intelectual ter trabalhado para tentar construir essas diferenças (OGIEN, 2003), contemporaneamente alguns pesquisadores têm analisado esse debate a partir da perspectiva bourdiana, de luta de classes simbólicas (LEITE, 2006). Nessa linha, o uso preferencial do termo erotismo para qualificar determinados objetos e práticas culturais informaria mais sobre o poder de uma determinada classe social para legitimá-las, em detrimento de outras que são denominadas como pornográficas, por serem supostamente menos elevadas/eruditas. Além do mais, emprego a expressão fabricação da monstruosidade para ressaltar a intencionalidade e o uso da criatividade e dos meios técnicos necessários para a construção desses personagens, para transformá-los em produtos vendáveis/compartilháveis de uma indústria cultural erótica em franco crescimento. Ao mesmo tempo, serve para diferenciá-lo dos demais processos de construção da monstruosidade, operadas, por exemplo, no âmbito da chamada cultura popular, no qual os símbolos e os sentidos são construídos e reconstruídos em um processo de longa duração, 
no qual os papéis de consumidores e produtores se mesclam e se confundem. Esse termo já foi empregado por Leha e Nascimento (2009), como título de uma obra por eles organizada, que agrega artigos que desenvolvem análises com perspectiva semelhante a esta, mas para o contexto da produção literária.

Pelo fato de serem produtos culturais, à primeira vista poder-se-ia imaginar que a monstruosidade, possuiria grande variabilidade de formas, já que teria como limites apenas o que é imposto pela criatividade humana e pelos contextos culturais, sociais e morais de um grupo em um dado tempo. Entretanto, como já observado por Courtine (2010), a fabricação da monstruosidade tem apresentado ao longo da história uma incrível estabilidade discursiva, estreiteza e repetitividade de estruturas e formas.

Mas a estabilidade narrativa dessas representações não deveria surpreender: o que se revela aqui é a dimensão antropológica, não histórica, deste imaginário do monstruoso, e com ela a dificuldade extrema de transgredir de outro modo que não seja o convencional os limites que a imagem do corpo humano impõe à representação de sua própria ultrapassagem. Estranho paradoxo: uma ordem quase mecânica reina sobre as figuras da desordem corporal extrema. (COURTINE, 2010, p. 501).

A dimensão antropológica ao qual se refere o autor imporia ao imaginário, juntamente com as convenções sociais de um dado tempo e lugar, os limites para se produzir o extraordinário: limites, por exemplo, quanto à anatomia geral, aos usos do corpo, ao gênero, à raça/etnia, à sexualidade, etc. 
No contexto da ampla indústria cultural contemporânea, fundamentalmente aquela protagonizada ou difundida por suportes e mídias sociais como a televisão, o cinema e a internet, chama a atenção o modo como particularmente a última década registrou um amplo investimento em narrativas e personagens conceituados classicamente ou traduzíveis contemporaneamente como do domínio do monstro. Uma rápida olhada nos campeões de bilheteria no cinema, ou mesmo dos livros mais vendidos torna possível apreender como imagem e imaginário sobre monstros e monstruosidades ocupam um lugar significativo nas sociabilidades e repertórios culturais contemporâneos. São monstros que se estabelecem e são lidos como tal a partir dos referentes da literatura e mitológica clássicas ocidental e oriental, do universo da ficção fantástica do romantismo, ou mesmo das tecnologias e enredos marcados pela sofisticação e suposição da ficção científica. Vampiros, lobisomens, híbridos de humanos e não humanos ou entre não humanos, existentes nesse planeta ou importados de imaginários sobre outras dimensões e lugares do tempo-espaço.

No interior da complexa indústria cultural, na qual são produzidas, difundidas e consumidas imagens de toda ordem, há o mercado pornográfico. A análise de produtos desse mercado, e no caso aqui, das animações pornográficas com personagens monstruosos, comercializadas na internet, é relevante se colocada em uma perspectiva mais ampla, no contexto da ampliação e diversificação do erotismo contemporâneo propiciado, em parte, por esse mesmo mercado. Segundo argumenta Maria Filomena Gregori:

Torna-se estratégico investigar as práticas que envolvem os erotismos, em meio a um universo que parece absolutamente central no mundo contemporâneo: o mercado. Além da constatação empírica de que esse 


\begin{abstract}
universo é significativo para as novas alternativas eróticas, parto do pressuposto de que ele constitui atualmente uma figura das mais paradoxais. Nesse cenário, reúnem-se experiências que alternam, de modo intrincado, esforços de normatização e também de mudança de convenções sobre sexualidade e gênero. (GREGORI, 2012, p.59).
\end{abstract}

Apesar dos desenhos animados pornográficos serem recentes na dinâmica cultural ocidental, pode-se afirmar, com base em Hunt (1999), que as representações visuais pornográficas são contemporâneas às textuais, e que a sua história se confunde com a própria história da modernidade. Apesar da pornografia enquanto objeto de consumo de massa cultural ter surgido apenas tardiamente, desenhos obscenos já eram empregados para ilustrar textos de caráter político, desde o século XVI, tendo como personagens preferidos religiosos, nobres, aristocratas ou políticos.

Embora a representação (textual ou imagética) de cunho erótico ou sexual possa ser encontrada em qualquer tempo e lugar, segundo Hunt (1999, p.10) “a pornografia como categoria legal e artística parece ser um conceito tipicamente ocidental, com cronologia e geografia particulares". E o seu desenvolvimento no ocidente, enquanto representação literária ou visual autônoma, visando, sobretudo, a excitação sexual de um público consumidor específico, ocorreu apenas ao longo do século XIX (HUNT, 1999).

A rápida expansão da pornografia ao longo do século XIX também evidenciou a existência de redes sociais bem articuladas de produção, distribuição, consumo e troca de pornografia impressa. Essas redes, formadas por escritores, ilustradores, fotógrafos, modelos, fornecedores, editores, 
distribuidores, livreiros e consumidores, funcionaram graças à construção de novos padrões de sociabilidade e solidariedade que foram capazes de burlar a censura e o controle social, e atender à crescente demanda do mercado consumidor. No Brasil, por exemplo, segundo Alessandra El Far (2004), a partir de 1870 a venda dos chamados "romances de sensação" (ilustrados ou não), e de cartões importados com fotos de mulheres nuas já era significativa, sobretudo no Rio de Janeiro. A princípio importados e reproduzidos (com ou sem licença), a grande procura por esse tipo de material motivou diversos editores nacionais a buscarem autores e modelos locais como forma responder adequadamente à crescente demanda doméstica.

No final do século XIX e início do século XX, com as transformações sociais decorrentes avanço do capitalismo industrial e o desenvolvimento e a difusão de novas tecnologias na área da comunicação, novos produtos e práticas de consumo erótico-pornográfico surgiram na Europa e nos Estados Unidos, se difundindo em um segundo momento para outras partes ocidente. Sem sombra de dúvida, uma das mais significativas foi a invenção do cinema, no final do século XIX (ABREU, 1996; GERACE, 2016). Antes do endurecimento da censura a partir da década de 1930, os filmes eram projetados em espaços coletivos, conhecidos à época como "cinematographos". Com o aumento do controle passaram a ser projetadas em estabelecimentos com cabines individuais, conhecidas como peeps shows, transformando o consumo em uma atividade mais individualizada (GERACE, 2016). Movimento similar ao que foi observado a partir do final da década de 1970, com a invenção do videocassete, apontado como um dos responsáveis pelo esvaziamento dos cinemas pornôs, sobretudo a partir do final dos anos 80 .

Apesar de a fotografia e o cinema serem invenções do século XIX, foi apenas ao longo do século XX que houve, de 
fato, uma ampliação e consolidação de uma cultura da visualidade e da imagem no ocidente, segundo Durand (2011). A imagem foi se "infiltrando" lentamente em diferentes meios e produtos culturais, tanto como elemento autônomo, quanto como uma nova estética na forma de organização dos elementos tradicionais. Em poucas décadas a linguagem e apresentação do jornal impresso irá apresentar uma nova estrutura mosaiquica, de certa forma multimidiática e hipertextual (SANTAELLA, 2004), novos estilos de texto serão desenvolvidos e o mais importante, uma nova mentalidade e sensibilidade foi sendo preparada para o consumo da imagem como meio e/ou fonte de informação e entretenimento. No campo do erotismo, as representações visuais também foram, paulatinamente, ocupando os espaços das representações textuais, predominantes até o início do século $\mathrm{XX}$, lembrandonos do esgotamento do sentido original da palavra pornografia (pórnê + graphos: literalmente, escritos sobre prostitutas), já observado por Roland Barthes.

Mas talvez tenha sido nas últimas décadas do século XX que possam ser observadas as mais rápidas transformações no mercado de consumo erótico, sobretudo em relação ao seu crescimento, diversificação e consolidação. Essas transformações foram resultantes de um conjunto de transformações políticas, econômicas, sociais e culturais ocorridas a partir dos anos 50, dentre as quais se destacam: a crise do sistema de acumulação capitalista e a sua reorganização, o avanço da globalização e de uma forma de organização internacional em redes (sociedades-rede), a transformação das tradições e dos costumes, o fortalecimento dos movimentos sociais, e a legalização da pornografia. Os avanços tecnológicos, na área de comunicação e informação, condições necessárias (mas não suficientes) para o desenvolvimento desses processos, tiveram um impacto significativo na transformação do mercado erótico, sobretudo 


\title{
Grotesco desejo: Erotismo, monstruosidade e internet desde a animação pornô
}

com as novas tecnologias de difusão cultural surgidas nesse período: Videocassete, DVD, o serviço de payperview via TV a cabo, e mais recentemente, a rede mundial de computadores. Essa ampliação e diversificação do mercado nas últimas décadas alçaram o erotismo e a pornografia à condição de elementos culturais "onipresentes" na cena social ocidental contemporânea, tal como já observado por Díaz Benítez:

\begin{abstract}
Mesmo de modo marginal, a pornografia faz parte de nosso cotidiano, daquilo que convencionamos chamar de cultura. Todo esse material "obsceno", entendido como algo off-scene, ou que deve se manter fora de cena, floresce em território público, ganhando protagonismo em nosso imaginário. (...) Vivemos em um mundo de sexo e somos obrigados a falar dele (DÍAZBENÍTEZ: 2010, p.12)
\end{abstract}

Além do mais, teria colaborado para o processo de aprofundamento da sua diversificação e especialização, tal como identificado por Gregori (2012), já apontado previamente. Tal dilatação faz parte dos dispositivos da sexualidade, que operam no mercado cultural de entretenimento. A transformação do Monstro em objeto também de desejo erótico/sexual, foi operada por mecanismos representacionais e discursivos potentes, que alteraram as formas como ao longo da história as sociedades e seus segmentos construíram as representações sobre esse "outro", deslocando-o do campo do misticismo, do sagrado e do científico para o campo do consumo, do lazer e do prazer.

O emprego do corpo monstruoso como objeto específico para o consumo erótico-pornográfico é mais recente, e parece coincidir com o enfraquecimento da monstruosidade como espetáculo público, a partir da primeira metade do século XX. 
Os produtos para consumo erótico-pornográfico (fotos, histórias impressas, quadrinhos, revistas, filmes em fitas de vídeos, DVDs, internet, etc), que tem como centralidade diferentes formas de monstruosidade (deformidades físicas ou comportamentais), sempre existiram, e se misturavam aos demais tipos produção sem nenhuma distinção. Mas essas produções, sobretudo a partir da segunda metade do século XX, foram gradualmente separadas das produções consideradas convencionais, e foram caracterizadas como um nicho específico de mercado, recebendo por parte dos produtores, do estado e dos consumidores uma abordagem e tratamento diferenciados (LEITE JUNIOR, 2006).

Enquanto objeto da indústria do entretenimento, a monstruosidade se diversificou e se proliferou na cultura contemporânea, em diversos setores e esferas da vida social. Diferente do que ocorreu em outros períodos da história, em que determinados tipos de monstruosidade foram predominantes (monstros míticos, teratológicos, híbridos ou fantásticos), na contemporaneidade haveria a difusão de todos esses tipos, produzindo de certa forma a sua banalização, uma tendência ao enfraquecimento de uma de suas principais características: a capacidade de produzir espanto e desconforto. O monstro não é mais exposto em praça pública, ou em museus, mas tornou-se personagem facilmente encontrado em diferentes produtos de consumo de massa, para as mais diversas culturas, gerações e classes sociais. São abundantes os brinquedos, as produções literárias, os desenhos animados, os filmes longa metragem, os jogos eletrônicos, as séries televisivas e as histórias em quadrinhos em que os monstros são os personagens principais ou os coadjuvantes (GIL, 2000). No campo da pornografia ocupam um lugar específico, apesar de ser percebida certa tendência ao espraiamento de uma estética do grotesco e do bizarro por outros tipos de produção nesse mesmo campo. 
Grotesco desejo: Erotismo, monstruosidade e internet desde a animação pornô

Nas últimas décadas, tem sido observada uma ampliação e diversificação do mercado de consumo eróticopornográfico com a abertura de novos espaços de sociabilidade, principalmente nos grandes centros urbanos, e pela produção e consumo de objetos culturais de massa de diferentes tipos, tais como roupas, acessórios e artefatos eróticos, publicações impressas, portais, sites, aplicativos, vídeos, filmes e animações pornôs. Tal processo, como apontado por Maria Filomena Gregori (2012), tem se dado no contexto de uma indústria cultural cada vez mais desenvolvida, para atender e explorar o processo de diferenciação social, por meio do consumo diferenciado de bens eróticos.

É preciso considerar também que a produção e o consumo desses bens acontecem de maneira segmentada, a partir de uma lógica de produção de objetos e espaços diferenciados para sujeitos diferenciados. Há, assim, intensos processos de organização, segmentação, corte, direcionamento, que fazem coincidir produtos-produtores-consumidores em uma rede de interação mediadas pelo desejo.

Como parte desse processo, nos últimos anos, tem proliferado na e através da internet um tipo particular de objeto cultural: os desenhos animados pornográficos. Esses desenhos estão inseridos em um conjunto amplo de ofertas de lazer e entretenimento caracterizados pela presença de um eixo ou teor erótico e sexual que circula em escala global através de plataformas e espaços de compartilhamento de arquivos digitais. A sua origem é diversa, e apesar de, conforme foi possível rastrear, uma parte significativa desse conteúdo ter sido, de forma ampla, produzido para portais de acesso pago, eles encontram-se dispersos de forma quase gratuita, bastando que o interessado tenha expertise para encontrar os espaços e disponha dos recursos técnico-informacionais necessários: conexão banda larga, perfil-conta para fazer o download ou upload dos arquivos. O consumo e a produção desses objetos, 
os vídeos pornôs em sua acepção mais ampla, configura assim um componente do fluxo de desejos e dos erotismos contemporâneos, estabelecendo uma estreita conexão com as reconfigurações do dispositivo da sexualidade em sua dinamicidade (FOUCAULT: 2013, p. 116; WILLIAMS, 2012; RUBIN, 2003).

No que tange às animações, no geral, são criadas para serem comercializados em diferentes sites de entretenimento para adultos, de onde podem ser copiados ou assistidos online em computadores pessoais, tablets e celulares smartphones. Entretanto, não é difícil ter acesso gratuito a parte desse material através de sites de compartilhamento de vídeo erótico, inspirados no youtube, onde são disponibilizados em pequenos fragmentos, muitas vezes como estratégia de divulgação e marketing. Em alguns desses sites as animações são disponibilizadas ao lado de outros tipos de vídeos e materiais pornôs, configurando uma categoria específica, em outros, são o seu principal ou único produto.

Assim como na maior parte dos desenhos animados contemporâneos, nos desenhos pornôs os personagens e os demais elementos que compõem as cenas (paisagem, cenários, objetos, etc), são representações imagéticas criadas digitalmente com o uso de tecnologia de computação gráfica. Também são criados digitalmente os sons e músicas que existem em praticamente todos os desenhos pesquisados. Em alguns casos, apenas os diálogos e alguns sons emitidos pelos personagens (quando existem, já que não se trata de um padrão), assim como alguns sons ambientes, não são criados digitalmente, mas gravados, tratados e inseridos de forma sincronizada às cenas.

Tal como observado em outros setores do mercado de consumo erótico, não há uma homogeneidade estilística nas animações pornográficas. Há desenhos que se aproximam das produções fílmicas "convencionais", com personagens e roteiros que, em maior ou em menor grau, os simulam. Outros 
Grotesco desejo: Erotismo, monstruosidade e internet desde a animação pornô

que se afastam desse modelo de representação da realidade e operam com desenhos menos realistas.

\section{A Animação do monstro}

Mesmo considerado o seu aspecto mutável e a situacionalidade configurada por contextos e encontros entre diferenças sociais e culturais, cada sociedade tende a produzir dispositivos estéticos e narrativos que conceitua como monstruosos, constituindo ali um espaço que é tanto expiatório para elementos percebidos como perigosos, como também produzindo fissuras que instauram esses mesmos seres enquanto espaços simbólicos para fruição erótica. $\mathrm{O}$ monstro assim é um ser caracterizado pela justaposição do sensual e do sensorial, daquilo que é difusor e difundido entre desejo e medo, continuidade e descontinuidade. É um ser que assegura a alteridade em um nível radical, ainda que informe tanto sobre aquele sujeito que o constituiu.

A pornificação do corpo monstruoso é um fenômeno característico dos processos sociais que promoveram sua inserção em uma indústria cultural onde ele participa como experiência de consumo. $\mathrm{O}$ seu lugar como produto cultural para as massas decorreu de um contexto favorável, no qual convergiram diversos aspectos: uma mudança das mentalidades e dos valores, as transformações nas representações e nos significados sobre a monstruosidade, uma ampliação das formas de difusão e consumo da pornografia e o florescimento de uma pornografia visual de massas - no campo da fotografia, do cinema, dos quadrinhos e da animação.

No caso da pornografia imagética e a sua reprodutibilidade técnica pode-se afirmar que seu caminho transcorreu paralelamente ao florescimento de novos meios e linguagens culturais de produção e difusão de imagens, 
convergentes e integradas, ou não, à reprodução de textos, sons e falas.

As condições para que esse tipo de representação fosse elaborada e consumida surgiram apenas no século XX. Nesse momento é que convergiram a representação imagética do monstro, o gosto popular pelo grotesco, o mercado da animação, a expansão da pornografia visual e de nichos específicos do mercado pornográfico dentro da categoria do "bizarro". Contudo, de modo mais amplo, a representação imagética da monstruosidade (maravilha, prodígio, fantástica ou humana) é tão antiga quanto suas histórias e descrições textuais. Tornaram-se mais frequentes na idade média, se materializando tanto em detalhes arquitetônicos (capitéis, fachadas, entalhes, etc.), quanto em ilustrações de manuscritos em xilogravuras em obras impressas (LÓPES, 2015; HERNANDÉS, 2015). A partir do século XVI estiveram presentes em obras de arte - quadros (DE LA FLOR, 2015) e gravuras impressas em folhetos para a divulgação de notícias e informes de interesse popular e em livros para consumo erudito. $\mathrm{Na}$ segunda metade do século $\mathrm{XX}$ com $\mathrm{o}$ aprimoramento da fotografia, surgiram as primeiras imagens de monstros em diversos formatos - carte de cabinet $(9,5$ por 14 $\mathrm{cm}$ e 11 por $16,5 \mathrm{~cm})$, carte de visite $(9,5$ por $6 \mathrm{~cm}$ e 10 por $6,5 \mathrm{~cm})$ e cartazes. As criaturas fotografadas eram personagens dos Freaks shows, sendo um dos mais conhecidos os apresentados no Barnum's American Museum, de propriedade do empresário americano Phineas Taylor Barnum. (SALVETTI JÚNIOR, 2013). Eram seres humanos com diferentes tipos e graus de deformações físicas, tais como gêmeos xifópagos, mulher barbada, homem elefante. Essas fotografias eram utilizadas para divulgar os shows e atiçar a curiosidade do público pelo exotismo dos corpos e do próprio suporte. No século XX, imagens de monstros humanos vão paulatinamente perdendo visibilidade e outros tipos de monstros ganham as telas do 
Grotesco desejo: Erotismo, monstruosidade e internet desde a animação pornô

cinema em produções clássicas do gênero do suspense e do terror, tais como: da adaptação do romance de Mary Shelley, Frankstein, de 1931 com direção de James Whale; King Kong de 1933; Lobisomem, de 1944 e A guerras dos Mundos de 1953, adaptação da obra de ficção de H. G. Wells. Entre estes se destaca Frankstein pelo pioneirismo e o fato de já nos créditos finais, na descrição dos personagens nomear o personagem como "Monstro Frankstein" - interpretado por Boris Karloff. Na animação seres fantásticos, monstruosos ou não, também se fizeram presentes desde a sua origem, como seria esperado de um gênero que desde os primórdios não buscou competir com a representação e encenação da realidade possibilitadas pelo cinema fílmico. Desenhos clássicos como Silly Sympony - The Skeleton Dance, com uma simpática orquestra de esqueletos, de 1929 e Betty Boop"s Penthouse, com um Frankstein afeminado, de 1933, dividem espaço com uma intensa produção contemporânea de antagonistas que assumem características de monstros desde os anos 1980, curtas ou longa metragem como, por exemplo, "A Bela e a Fera", com produção dos estúdios Disney.

O longo caminho que percorreram as imagens dos monstros, do imaginário e elaborações populares, passando pelas divagações e reflexões teológicas, filosóficas, científicas, literárias e artísticas, implicaram múltiplos fluxos e processos de agregação, desmembramento, fragmentação, recomposição, perda, resgate, ressignificação, reconstrução, fabricação de signos, significados e linguagens nesses e entre esses diferentes campos. A pornografia, como parte constituinte desses fluxos em uma sociedade que constantemente incita a fala sobre o sexo, acaba por incorporar também esses referentes e produzir versões erotizadas para situações e personagens variados, dos quais o monstro não é exceção.

No gênero da pornografia hard core mainstream a pornificação dos corpos e do sexo é baseado em uma série de 
elementos, que vão desde a forma de apresentar as cenas, os enquadramentos de câmera (primeiríssimo plano, moneys shots, câmera subjetiva, etc), o emprego de recursos sonoplásticos específicos para se criar uma "paisagem visual" que reforce o prazer visual encenado, passando pela escolha de cenários, figurinos e a seleção dos atores com biótipos específicos (virilidade, pênis brande e com ereção fácil e potente para homens, sensualidade, ausência de cicatrizes e sensualidade para mulheres, e sensualidade e perfeição na construção de um corpo feminino no caso das travestis)viris e com pênis grandes capazes de manter a ereção por longos períodos para os homens e corpos bem definidos e bunda grande para as mulheres), e, por fim, a forma como a história e a narrativa serão roteirizadas (ABREU, 1996; DÍAZ-BENITEZ, 2010).

Em sua pesquisa sobre a produção de filmes pornôs no Brasil, Maria Elvira Díaz-Benitez (2010) observou que a história e a narrativa pornô encenados eram roteirizados segundo um certo padrão, ou modelo, que denominou como "sexo coreografado". De forma mais detalhada, ela descreve que o "sexo coreografado" seria a sequência de atos ou cenas sexuais, e os seus ritmos, que os filmes hard core orientados pelo mercado para o consumidor heterossexual tem que apresentar, para serem consideradas produções potencialmente rentáveis. Nas produções fílmicas investigadas, produzidas principalmente no Rio de Janeiro, o "sexo coreografado" implicaria em cenas organizadas na seguinte estrutura: a) beijos rápidos e ardentes, $b$ ) beijos rápidos nos seios/peito, c) sexo oral, d) penetração vaginal - dedos e/ou pênis, e) penetração anal. Apesar de variações em cada uma dessas cenas, ela observou que as suas durações, depois de editadas, não costumam ultrapassar cinco minutos, em média. Esse roteiro associado aos cenários, vestimentas, enquadramentos de câmera, paisagem sonora, narrativa e certos biótipos 
Grotesco desejo: Erotismo, monstruosidade e internet desde a animação pornô

conformariam a pornificação dos atores em cena e produziriam o erotismo esperado de um filme desse gênero.

Partindo do pressuposto de que o mercado do sexo é altamente especializado e profissionalizado, com diversas convenções e modelos estéticos, narrativos e visuais sobre a representação do corpo, do sexo e dos prazeres, que orientam a produção e o consumo dos diferentes tipos e gêneros de produtos pornográficos, é razoável supor que no campo das animações algumas convenções e modelos sobre o erótico também existam e operem como "pontes" de sentidos e significados produtores e consumidores.

As animações pesquisadas poderiam ser organizadas, segundo a perspectiva de suas estruturas narrativas, ou de uma coreografia dos sexos, em basicamente três grandes modelos. $\mathrm{O}$ primeiro são animações que apresentam cenas de EncontroImobilização-Sexo, ou seja, apresenta informações que contextualizam e justificam a co-presença entre personagens marcadamente diferentes, seguido de cenas que representam o conflito e o controle dos personagens atacados pelos monstros, finalizando com cenas de sexo propriamente ditas. Também há animações com cenas de Encontro-Sexo ou Imobilização-Sexo, e aquelas apenas com cenas de Sexo.

Nas animações "Wildcat vs Gorillaman", "3Dteen girl and two monster hard fuck", "House of erotic monster" e "Blonde gang banged by huge orc monsters cock", por exemplo, pudemos observar, guardadas algumas pequenas diferenças e variações entre as cenas, apresentam uma estrutura do tipo E-I-S que poderia ser detalhada no seguinte sequenciamento de cenas: a) O início, via de regra, é marcado por um encontro inesperado entre o monstro e a outra personagem; b) Há algum tipo de perseguição, golpe e imobilização; c) Penetração vaginal enérgica/violenta; d) gozo interno e abundante do monstro, com dilatação da barriga e vazamentos dos líquidos injetados (que será melhor descrito e analisado à frente); e) Sexo oral; e) 
nova cena de gozo abundante do monstro. Em "(FFXII) Dalmascan Nigth Final Fantasy XII" uma animação também com estrutura E-I-S, já há um roteiro um pouco diferente, sobretudo nas cenas de sexo: a) Encontro inesperado com o monstro; b) Ela é imobilizada; c) $\mathrm{O}$ monstro utiliza um vibrador; d) $\mathrm{O}$ monstro injeta um líquido, com uma seringa, na vagina e no anus dela; d) Cena de penetração vaginal sem gozo do monstro. Em "[A third dimension] Little Ballerina Hina Bitch! 2 Endless Bad End", uma animação apenas com cenas de Sexo (estrutura S), vemos: a) sexo oral do monstro na mulher; b) penetração múltipla com tentáculos; c) penetração vaginal violenta com pênis; d) penetração vaginal com dedos do monstro (não há cena de gozo). Em diversas outras animações com estrutura $S$, sobretudo nas com menor tempo de duração, as cenas de sexo se restringem a uma variação menor de tipos de penetração, como por exemplo em "Anime sex prisoner fucking huge dick squirts tones" que se limita a duas rápidas cenas: a) a jovem garota é penetrada por um braço mecânico de uma máquina, b) é penetrada vigorosamente por uma criatura prateada que goza abundantemente no final. Ou em "Captive Cassandra [StudioFOW]" onde a personagem é penetrada violentamente pela criatura enquanto é segurada ora pelas mãos, ora pelo pescoço. $^{2}$

2 Duas das animações citadas "(FFXII) Dalmascan Nigth Final Fantasy XII" e "[A third dimension] Little Ballerina Hina Bitch! 2 Endless Bad $E n d "$ foram excluídas do site no intervalo de tempo compreendido entre o trabalho de campo, quando foram visualizadas e registradas no diário de campo (dias 24 de abril de 2016 e 18 de maio de 2016, respectivamente), e o final de novembro de 2016 quando se tentou o acesso pela última vez. A primeira tinha 20 minutos de duração, havia sido visualizada mais de 5,8 milhões de vezes, contava com uma avaliação positiva de $100 \%$ e 5 comentários. A segunda tinha 27 minutos de duração, havia sido visualizada mais de 49 mil vezes, tinha uma avalição positiva de $99,01 \%$ e 30 comentários. Os avisos 
Nas animações pesquisadas a pouca presença de cenas de beijo e de carícias nos seios das personagens femininas, acompanhado de cenas de imobilização e/ou violência explícitas, ou apenas cenas de sexo oral, de penetração vaginal ou anal com dedos, pênis, estruturas fálicas ou dildos apontam para a fabricação de um tipo de pornificação dos corpos e do sexo que opera com outro registro, negando signos de afeto e carinho e reforçando signos de sexo violento ou pelo menos não intencional e impessoal. Nesse sentido, podemos afirmar que nas animações com monstro pesquisadas há uma tendência em se priorizar o que poderia ser denominado como "mecânica do sexo", onde a eixo narrativo das histórias está centrado na máxima visualização das penetrações, que não são necessariamente violentas, mas que exploram os corpos dos personagens ao máximo. No caso do corpo monstruoso as suas qualidades excepcionais ou faltas. No caso dos outros personagens, corpos impossíveis que resistem às investidas.

O processo mais recorrente na inserção do monstro como objeto de erotização pornográfica é a produção de uma estética marcada pela diferença e pelo contraste entre formas, texturas, velocidades, sonoridades, enfim, tudo que informa uma noção ampla de "cinestesia", ou seja, essa justaposição entre intercambialidade sinestésica de sensações e de movimentos a partir da qual o pornô se desenha. Nos termos desse trabalho damos ênfase a algumas situações episódicas em que esse jogo de cinestésico de contrastes se estabelece de maneira mais evidente, a saber: o modo como corpos humano e monstruoso se engajam em um jogo entre dilatação, transparência e uma busca pela excitação e efeito de efetividade a partir da interioridade do corpo animado, bem como a

encontrados nos sites no momento em que se tentou visualiza-las novamente foram: "Desculpe, este vídeo foi excluído" e "Este vídeo foi excluído por problema de direitos autorais, a pedido de DMM.". 
inserção de uma certa câmera subjetiva e o próprio gozo, aqui como situação de ápice.

\section{Transparências e dilatação: o sexo visto por dentro}

Uma das características mais importantes das produções pornográficas visuais e audiovisuais é, sem sombra de dúvida, a exibição dos corpos, das expressões e do sexo de maneira direta e de perto, sem empecilhos e velamentos que impeçam de apresentá-lo para a audiência. É preciso mostrar tudo, ou quase tudo que reforce $o$ caráter excepcional do sexo representado, um "Frenesi do visível" nos dizeres de Linda Williams (1999). Nas animações também não é diferente. Os corpos são explorados em sua intensidade, de modo a exaltar os traços que caracterizam corporalmente cada um dos seres através de músculos, fluídos, expressões faciais, sons e mesmo da diluição de materialidade do corpo através de estratégias como a transparência e a dilatação ou deformação, bem como através do transporte para uma dimensão usualmente não acessível aos olhos. O corpo assim é explorado tanto na sua superfície quanto sua interioridade, como a confirmar as sensações e mesmo as posições que cada personagem ocupa no sistema de relações.

Uma das soluções empregadas para potencializar essa característica é um recurso que, na ausência de um termo melhor, poderia chamado de "transparência" dos corpos, que poderia ser descrito como uma atenuação temporária da opacidade do corpo, para permitir a observação do sexo, dos corpos e das personagens de ângulos ou perspectivas que não seriam possíveis sem o emprego desse recurso.

No corpus analisado duas animações ilustram de maneira radical o efeito da transparência dos corpos na produção dos encontros eróticos entre monstros e humanos. Em "Anime sex prisioner fucking huge dick squirts tones" a criatura 
apresenta um corpo prateado e partes do seu corpo em determinadas cenas, como na em destaque, tem uma transparência parcial e gradativa que permite a visualização da reação e expressão facial da jovem personagem feminina durante a penetração. Por sua vez, em outra animação chamada "3D teen girl and two monster Hard Fuck" é empregado o recurso da transparência total dos corpos das criaturas que dominam a jovem personagem. Na sequência das duas cenas é possível observar o apagamento quase completo do corpo do ogro, permanecendo apenas leves traços do seu contorno, para dar destaque ao sexo, ao corpo e as expressões da personagem dominada.

Algumas animações, sobretudo as de origem orientais (japonesas), apresentam um curioso recurso de imagem: a apresentação de uma visão interna do corpo e do sexo, ou seja, da penetração com o pênis, ou de algum órgão-prótese-pênis do monstro, tais como: tentáculos, sondas e prolongamentos do corpo os mais variados, em alguma, ou em múltiplos orifícios e cavidades do outro corpo, normalmente feminino, tais como ânus, boca, vagina, orelha ou nariz. Esse recurso quando empregado é apresentado, normalmente, como um detalhamento, em uma pequena "janela" em primeiro plano, da cena da penetração que continua a ser representada em segundo plano. Dessa forma podemos visualizar simultaneamente o que se passa por dentro e por fora dos corpos penetrados.

Nas imagens abaixo há três exemplos do emprego desse recurso. Na primeira, extraída da animação "3d natural slave nekoken", a personagem, uma jovem garota branca de cabelos ruivos é penetrada e, por alguns segundos surge uma pequena janela no canto superior direito da tela que apresenta o detalhe dessa penetração. Em outra animação, "Depths of the Dungeon 3", uma jovem personagem é penetrada por vários tentáculos e há uma janela no canto inferior da tela que apresenta detalhes 
da dupla penetração. Mas diferentemente do exemplo anterior, observa-se um maior detalhamento das estruturas anatômicas internas do corpo feminino, supostamente mais realistas. A terceira cena foi extraída de uma animação intitulada "Kunoichi Broken Princess Edit", que se aproxima de uma estética mais realista, que pode ser observado pela qualidade dos gráficos e dos efeitos visuais empregados. Tal como no segundo exemplo, a imagem interna tenta reproduzir detalhes anatômicos internos para conferir maior "realidade" à animação.

Já na animação "A Third Dimension - DLC EX", uma jovem bailarina presente em outras animações da série " $A$ Third Dimension" é dominada e violentamente penetrada por uma criatura demoníaca gigantesca, com imensas garras, língua, tentáculos e pênis. As cenas com as imagens internas são alternadas com as da penetração improvável, como forma de reforçar a sua "veracidade" e, nesse caso em particular, é utilizado como recurso de dramaticidade, pois a intercalação de cenas (externas e internas) devem ter sido pensadas para reforçar a violência da penetração imposta. A violência do ato se completa com as expressões de dor da personagem e a "paisagem sonora".

Se uma das concepções sobre a pornografia é a do exagero e da ampliação de uma suposta realidade do sexo, com o emprego de zooms dos genitais e da penetração propriamente dita, um sexo coreografado em ângulos que dificilmente seriam possíveis sem o emprego de posições, efeitos de iluminação e de câmeras especiais, podemos considerar o emprego do recurso da visão interna como o grau máximo de uma forma de representação sobre uma "hiper-realidade" do sexo, mesmo que a imagem apresentada, nesse caso, não seja a de corpos humanos de "carne e osso", mas de corpos digitalmente criados e animados.

Possivelmente esse recurso tenha sido uma resposta criativa às peculiaridades da linguagem e da estética da 
animação, no qual o emprego de zooms e closes das cenas de sexo não produz efeito similar ao obtido no cinema. Nos filmes pornográficos o zoom apresenta, além de uma imagem ampliada e próxima do sexo, os detalhes dos corpos dos atores: a pele com suas reentrâncias e rugosidades, os pelos, as secreções, o suor, o tensionamento dos músculos, etc. Nas animações o zoom não amplia detalhes e revela os pixels do desenho, já que não existem detalhes ocultos na imagem criada para serem revelados.

Quando empregado nas animações, esse recurso reforça a excepcionalidade do corpo e do sexo monstruoso, em oposição à normalidade do corpo e do sexo não monstruoso. $\mathrm{O}$ pênis ou qualquer outro órgão do monstro que possa ser utilizado para penetrar, invade cavidades internas improváveis, força a passagem por estruturas e mucosas internas até então intactas, penetram em áreas que o pênis humano nunca alcançaria.

O emprego de imagens internas também é encontrado em produções fílmicas pornôs hard core. Em produções desse tipo há a instalação de uma micro câmera, do tipo das utilizadas para exames médicos, no interior do canal vaginal da mulher para mostrar para a audiência, uma visão da penetração e da ejaculação masculina, de dentro e de perto. Outra possibilidade é produzir as imagens, "de fora para dentro", do canal vaginal ou do reto, com a utilização de um espéculo (aparelho para exames ginecológicos e proctológicos), que os abre e os expõe, e com uma câmera com um bom zoom e uma boa resolução. O resultado final do emprego desses recursos não é muito satisfatório quando comparado aos obtidos pelos jogos de câmera e iluminação externos, o que talvez explique porque são pouco empregados e o pequeno número de produções disponíveis para consumo.

Torna-se curioso o fato desse recurso empregar imagens que tentam simular detalhes anatômicos comporem que, se não 
correspondem à representação de imagens reais das estruturas internas dos corpos femininos, são apresentados como se fossem. O emprego desse tipo de recurso e imagens só é eficiente porque reporta a um conhecimento e imaginário sobre a anatomia humana que são de conhecimento popular devido à institucionalização e difusão promovido pela biomedicina. Como já notaram pesquisas em outras áreas temáticas, principalmente aquelas vinculadas aos discursos e práticas do saber biomédico e da tecnologia, a visão é um órgão hipercentrado e mobilizador de certa verdade. Enxergar além é uma competência desses campos de ciência, como mostram os trabalhos de Paula Machado (2008) e Emily Martin (1996), ainda que, conforme notaram Anne Fausto-Sterling (2000) e Donna Haraway (1995), essas tecnologias de olhar se dirijam a uma dimensão de interioridade sofisticada e que se traduz na tentativa de encontrar uma verdade irredutível que esteja na dimensão microcelular, por vezes ignorando as relações e interações que se estabelecem no meio social e são ordenadas culturalmente.

Nesses termos, a busca de uma verdade sobre o sexo com base na observação do interior celular, anatômico, enfim, na dimensão profunda da pele encontra eco e forma também no campo da pornografia. Aqui, observar o interior é quase uma tecnologia-protética que busca garantir a verossimilhança da representação. A visão interna no caso das animações pesquisadas é mais potente do ponto de vista estético, apesar de menos realista do que as das produções fílmicas, pois é possível se posicionar a "câmera" (ou seja, o olho do observador audiência) em qualquer posição da cena (distância e ângulo), sem as limitações técnicas e corporais que são impostas na utilização das micro câmeras ou dos espéculos nos corpos "reais". Na verdade, mais que uma visão "por dentro", trata-se, na maioria dos casos, de uma visão "sobre o que se passar por dentro" do corpo. 
É observando o que ocorre dentro em uma relação profundamente marcada pelo contraste e pela diferença que o sexo enquanto encontro entre seres percebidos como radicalmente distintos assume uma conotação de "como se fosse" verdade. A penetração se confirma assim como a justaposição dos corpos, e a velocidade, intensidade, friç̧ão produzido através desse recurso garantem certa inteligibilidade da situação como fundamentalmente erótica. Se, por vezes, a pornificação se estabelece sem o advento dos momentos preliminares e das trocas de carícias, estando a excitação submetida à violência quase imanente dos encontros, observar dentro e o que ocorre dentro é uma espécie de confirmação dos contrastes e das diferenças que mobilizam fluxos e produzem excitação.

As imagens internas nas animações não são os únicos recursos estéticos que demonstra a monstruosidade do sexo e a excepcionalidade dos corpos das criaturas nas animações pesquisadas. As deformações dos corpos penetrados também são muito observadas, sendo particularmente frequente a deformação/dilatação do ventre/barriga e em menor escala a das bochechas.

Em duas animações da amostra analisada, as situações de erotização e encontro entre monstro e humano orbitam fundamentalmente em função desse aspecto que parece simular uma relação de possessão e dilatação dos próprios limites do corpo humano. Em “少女拡張 chap.1/ shoujo kakutyou” (tradução livre: "A Expansão da Menina"), por exemplo, um monstro de pele azul e tamanho incrivelmente desproporcional possui o corpo de uma jovem menina.

A cena de pouco mais de seis minutos, e possivelmente recorte de uma obra maior a qual não foi possível ter acesso, é marcada por uma paisagem visual que parece ser elaborada em ritmo lento. $\mathrm{Na}$ animação o início estabelece-se já com a penetração, a estrutura peniana do monstro é borrada e a jovem 
parece lamentar, reclamar, enquanto seu corpo, principalmente sua barriga vai expandindo-se pelo contato genital com a figura monstruosa. A obra parece compor uma série de várias situações denominadas capítulos onde a jovem menina de cabelos azuis é sucessivamente desafiada e possuída pela presença de seres monstruosos dos mais variados tipos. Em algumas situações, a exemplo do capítulo 1, a jovem parece em si mesmo ser também um monstro, o que se denota pela presença de chifres e do cabelo azul, apesar de toda a anatomia e conduta ser bastante simular à própria anatomia feminina humana.

A juventude feminina e o aspecto recatado parece ser outro elemento reiterado nas animações. É o perfil, por exemplo, da bailarina protagonista de "Little Ballerina Hina Bitch!". A menina de cabelos negros e expressão jovial tem seu destino alterado quando se depara com um monstro em caracterizado como um ser vermelho de aspecto antropomórfico e um tanto demoníaco. A consistência parece ser viscosa e seus olhos brilham de modo destoante de todo o movimento corporal em um tom amarelado. Além dos braços o monstro apresenta um tentáculo cuja ponta abre-se em três pétalas a partir de onde se pode ver seu interior. A animação de pouco mais de 35 minutos é composta por 4 cenas que tendem a iniciar com uma pequena apresentação da personagem feminina, uma bailarina, que nua ou em roupas curtas e transparentes começa a se tocar nos seios e genitália até ser encontrada pelo monstro. O cenário é um plano de fundo onde por vezes aparecem móveis ou objetos que denotam uma casa, uma sala de dança, um ringue de boxe ou um palco.

Nas diversas cenas que compõem esse desenho a jovem mulher é invariavelmente penetrada pelo monstro quase sempre por trás, ocasião na qual o tentáculo emerge como para romper o ritmo da cena e a penetra de modo inesperado. 
Não raramente, muitas das animações aqui analisadas são marcadas e classificadas através da tag "3D". É possível sugerir, no escopo das questões aqui tratadas que essa tag refere-se não apenas a uma estética distinta, resultado da animação digitalizada e da apresentação dos corpos de maneira a evidenciar sinais de volume e profundidade, por exemplo. Trata-se fundamental de um registro das próprias formas de interação eróticas mediadas através da e na animação pornográfica. Isso quer dizer que, em muitos aspectos, as tecnologias de exposição de corpos em sua interioridade e plasticidade sinalizam não apenas para a possibilidade de sofisticação técnica, mas antes para as relações de continuidade e proximidade que a animação estabelece para com a pornografia convencional.

A deformação do corpo não monstruoso não é um recurso exclusivo das animações. Na pornografia hard core podem ser encontrados em filmes de diversos gêneros em que há cenas de sexo oral, ou então, em um gênero específico de filmes considerados bizarros, em que há cenas de penetração com as mãos (fisting). Essas práticas misturam modalidades de sexo convencional, a exemplo da penetração anal ou vaginal, a formas de experimentação marcadas pela tensão e provocação dos limites do corpo e da sensação entre violência, perigo e dor através da utilização de partes do corpo, a exemplo das mãos, no caso da pornografia hard core, ou de prolongamentos como cabos e tentáculos, no caso das animações aqui analisadas. Nesses termos, as representações em estudo se relacionam também com uma dimensão particular de "maravilhoso" e "prodígio" do corpo animado. Trata-se de produzir uma experiência que seja espetacular não apenas pela característica dos seres que estão em interação, mas sobremaneira pelo recurso do inesperado.

\section{O Gozo monstruoso}


A ejaculação ocupa um lugar central nas produções hard core contemporâneas. Não é um ato a ser ocultado, dissimulado, ou para ser deduzido através de movimentos, sons, ou qualquer outro artifício, ou efeito da filmagem e edição, como é comum nos filmes do gênero soft core. $\mathrm{O}$ gozo deve ser sempre exibido para as câmeras (e para a audiência), como prova incontestável da veracidade do ato sexual e do prazer masculino (WILLIANS, 1999). No sistema de distribuição das responsabilidades eróticas que o sexo encena, o gozo masculino ocupa uma dimensão pública e se converte em evidência da excitação, e por si só mobilizador da potentia gaudendi.

A ejaculação, o gozo, é um dos recursos que possibilitam que a audiência possa "se ver" na tela, possa se projetar no filme, e desta forma produzir para si prazer e satisfação. Essa tomada de cena, em close, também ficou conhecida como money shot, come shot ou ainda cum shot. O gozo para as câmeras, fora da cavidade vaginal, anal ou oral, comporia uma das duas componentes paradigmáticas da iconografia pornográfica hard core, sendo a outra, a exibição em close (dos genitais e da própria relação sexual), como já mencionado anteriormente. Como já disse Stephen Ziplow "se não há money shot não um filme pornô" (citado por ABREU p. 96). A expressão money shot originalmente se referia, às cenas, ou planos de cena que eram muito onerosas para serem produzidas. $\mathrm{Na}$ produção de filmes pornôs adquiriu $\mathrm{o}$ significado de cenas ou planos de ejaculação pelo fato dos atores, nos primórdios do gênero hard core ganharem cachês adicionais para a sua gravação. Também teve esse significado reforçado por evidenciar o sucesso e os lucros que essas cenas no hard core alcançaram a partir da década de 1970.

Apesar da importância do gozo como elemento narrativo, estético e estruturante do gênero hard core, ele é recente na história da representação fílmica do obsceno. Como 


\section{Grotesco desejo: Erotismo, monstruosidade e internet desde a animação pornô}

lembrou Abreu (1996), o primeiro filme a ser reconhecido por mostrar a ejaculação masculina como "evidência visual do prazer masculino pelo espasmo involuntário e incontrolável do clímax do orgasmo" (ABREU, 1996, p. 65), foi Garganta Profunda (Deep Throuath), lançado em 1972. Antes de Garganta Profunda a ejaculação masculina era raramente mostrada nas telas pois, além de imoral, era considerada sem relevância para a estética da pornografia visual nos primeiros três quartos do século XX. Antes de Garganta Profunda o gozo masculino foi registrado em alguns stag films ${ }^{3}$ e filmes amadores de curta duração.

As transformações que introduziram o money shot como elemento obrigatório na filmografia pornô foram graduais e lentas. Havia barreiras morais e legais tanto das agências de regulação, quanto das distribuidoras, salas de cinema e do público em geral, a necessidade de cambiar a mentalidade dos atores e se experimentar novas formas de apresentá-lo no vídeo que explorasse ao máximo as suas potencialidades eróticas.

Já o gozo feminino no gênero hard core dramaturgicamente tendeu a ser tratado como menos importante do que o masculino. A excitação e toda a gama de sentidos que conferem à cena um aspecto de interesse e envolvimento são produzidas a partir de referentes verbais, como gemidos e pequenas frases, além de expressões corporais. Além de uma questão de gênero, que implica um papel e uma posição de maior submissão na pornografia audiovisual, o corpo da mulher não produziria, tal como o do homem, uma

3 "Stag films" é o termo pelo qual ficou conhecido uma série de produções pornográficas clandestinas, em sua maioria da primeira metade do século 20, nos primórdios do cinema como experiência de exibição pública. Eram filmes que tratavam cenas pouco convencionais ou protagonizadas por atores e atrizes de menor prestígio no circuito pornográfico. Também costumavam ser exibidos em bordeis (WILLIAMS, 1999). 
evidência visual direta, explícita, um discurso de verdade, sobre o prazer encenado. Na ausência dessa "verdade visual", o gozo feminino tem sido demonstrado por meio de uma "imagem sonora do prazer", através de uma ampla gama de gritos e gemidos, que captados diretamente na gravação, ou inseridos a posteriori na edição do filme, compensariam essa falha original (ABREU, 1996; DÍAZ-BENITEZ, 2010).

Nas animações pesquisadas essa componente da narrativa e forma de representação estética não é diferente. Nelas, o gozo do monstro também é considerado elemento visual e sonoro importante que deve ser mostrado. Em geral, trata-se da ejaculação de um fluído, ralo ou espesso, branco ou com outra cor qualquer, e exageradamente abundante. A abundância do gozo, em seu aspecto simbólico e narrativo acaba funcionando como representação pictórica de todos os referentes dos quais os monstros masculinos estão embebidos: vigor, força, potência, virilidade.

Entretanto, diferentemente do que ocorre nos filmes pornôs hard core, pôde-se observar que o gozo monstruoso ocorre geralmente dentro dos corpos, e não fora deles, para ser exibido para as câmeras em money shot. Apesar de ocorrer dentro dos corpos o gozo não é ocultado. O que há é a sua apresentação de forma indireta, através da deformação do corpo penetrado - expansão violenta do ventre, bochecha, garganta, e outras cavidades, ou pelo vazamento das secreções. Em alguns desenhos, inclusive, os vazamentos se dão por outros orifícios, que não os penetrados, reforçando a ideia de violência/prazer na representação do sexo e da sua monstruosidade.

Nas animações, dessa forma, observamos que há outra forma de representação visual do prazer masculino, ou seja, do prazer monstruoso que assume o lugar de masculino na representação. Raramente há o gozo exibido diretamente para a câmera. O mais comumente encontrado é a sua apresentação 
Grotesco desejo: Erotismo, monstruosidade e internet desde a animação pornô

indireta por meio da deformação do corpo penetrado ou através dos fluídos que dele escapam, devido sua abundância. Assim, pode-se afirmar que as animações preservam o elemento narrativo - a evidência do prazer pelo gozo, que caracteriza o gênero hard core, mas altera a forma de apresentálo, atualizando-o de acordo com as potencialidades e as características estéticas da linguagem da animação.

Note-se também que o gozo, na animação, é um atributo de toda forma masculino, não importa se orgânica ou não. Em uma animação de nome "Giant robot destroys space girl" um monstro autômato com pênis de tamanho quase equivalente ao seu próprio braço adentra uma nave espacial e toma por assalto uma das suas tripulantes, uma mulher representada como humana de seios fartos, pele branca e aparência jovial. $\mathrm{O}$ resultado do encontro inesperado é simultaneamente jocoso e violento. Observa-se o sinal da ejaculação do monstro-máquina tomando o corpo da moça dentro do seu corpo, de modo que uma grande quantidade de líquido expande o seu ventre violentamente.

Algumas poucas exceções a esse perfil de gozo internodistensão foram encontradas no contexto das animações analisadas. Exemplo dessas exceções são as animações " $3 D$ Monster Fucking" e "Amusteven Velna 3 the Animation", em que as cenas de sexo e as que representam gozo são muito próximas às tradicionais à money shot. Nelas a ejaculação é celebrada como exibição externa e pública, sinal de potência e sucesso na satisfação de um desejo particular e executado de maneira que pode ser caracterizada como violenta.

A segunda animação em particular, "Amustevan Velna" é parte de uma série produzida por Amusteven, um animador autônomo, para uma produtora chamada Affect3D, e cuja principal personagem é uma aventureira ou guerreira mais ao estilo Indiana Jones. Na animação ela é tomada por criatura bizarra logo após retirar uma espécie de objeto sagrado de um 
altar. Esse encontro culmina com a situação erótica na qual a criatura penetra a aventureira. Entretanto, apesar da excentricidade da criatura e do próprio cenário, uma espécie de templo com elementos arquitetônicos referências às tradições greco-romanas clássicas, as cenas de sexo são convencionais e alinhadas ao roteiro e à narrativa dos filmes hard core. Diferentemente de outras animações não há cenas de violência, há momentos mais eróticos e cenas de sexo/penetração mais convencionais, e ao final, uma cena de gozo estimulada pela masturbação da personagem ao estilo money shot. Inclusive há o emprego de uma repetição da cena, sobre outro ângulo e perspectiva, como forma de prolongar o frenesi dessa imagem, também muito explorada no cinema pornô mainstream.

O vazamento do gozo do monstro do corpo feminino tem certas semelhanças com algumas cenas de eliminação do esperma retratados em filmes hard core, em que há cenas de barebacking - sexo sem preservativo, vaginal, oral ou anal, e no qual a atriz (ou ator, no caso de filmes homo, bi ou trans) mostram para a câmera, em close, o esperma saindo do seu corpo depois do ato. Também guardam semelhanças com cenas de algumas produções fílmicas pornôs com estilo dominador, fetichista ou bizarro nas quais há a inserção de líquidos, pelo ânus ou vagina, no corpo feminino (ou masculino, no caso de filmes homo), tais como leite ou bebidas gaseificadas (cervejas, refrigerantes, espumantes, etc.), seguido da exibição da sua expulsão. Nesses casos, é evidente que esses líquidos inseridos e a sua expulsão se referenciam ao gozo masculino, evidenciando como se tornaram uma referência narrativa importante nesses gêneros audiovisuais.

\section{Considerações Finais}

Se é verdade que o pornô é uma mercadoria inserida dentro de uma indústria cultural que mercantiliza o sexo 
coreografado como forma de produto, por outro lado não é possível ignorar o modo como através do filme se projetam representações de relações que são potentes na arena do social enquanto experiência. Narrativa e experiência juntas estabelecem um compósito, um aglutinado sofisticado que não pode ser ignorado ou deixado de lado.

Através de uma sofisticada tecnologia narrativa, a pornografia possibilita que a experiência de atores se transforme em um lócus de representação de questões e aspectos da vida coletiva que são amplos e ocupam posições variadas, estejam elas no campo das convenções, das expectativas ou mesmo dos interditos. Nesses termos, pensar o pornô pode ser assim também uma forma de pensar como as sociedades organizam-se e atribuem sentido às suas práticas, concebendo-as como mais ou menos possíveis, como mais ou menos legítimas ou valorizando-as em múltiplas hierarquias. Mais ainda, se o pornô é uma rede de circulação de informação, é preciso considerar então que essas hierarquias em alguma instância podem informar mais sobre seu uso dentro de uma perspectiva discursiva do que propriamente numa perspectiva das sociabilidades e práticas cotidianas. Permanece assim a ideia de que se o pornô é diverso em estética e em consumidores, isso não implica uma menor disputa política (interna e externa a produtores e comercializadores) sobre quais formas de representação sobre o sexo são mais ou menos concebíveis ou "publicamente" aceitáveis.

Apesar da pornografia, um dos temas-eixo desse trabalho, ter sido elevada nas últimas décadas à categoria de objeto de pesquisa acadêmico em diferentes campos das ciências sociais, das artes e da filosofia, há que se reconhecer que, ainda hoje é considerada por muitos como tema menor ou marginal. Ademais das dificuldades que a manipulação do material e a atmosfera negativamente moralizada com que se enxerga o tema frente a questões que se anunciam como mais 
urgentes, há em última instância a suposição de estaríamos tratando aqui de um tema sobre o qual não há muito a dizer. Aliás, essa impressão de precariedade que circunscreve o imaginário social sobre o pornô talvez seja sua concepção mais característica e ambivalente. No mundo ocidental urbano o pornô ocupa essa posição ambígua de ser consumido por grandes massas e ao mesmo tempo ser predominantemente individual, de estar nos DVDs, computadores e smartphones e ao mesmo tempo ser tão silencioso. Os gemidos e sussurros de atores e atrizes, animados ou não, provocam assim esse complexo de ambivalências que constituem a especificidade de uma sociedade tão comprometida em produzir espaços de fala sobre o sexo e de controla-los tão incisivamente. Essas são produções pequenas, para serem consumidas de maneira rápida e que, ao mesmo tempo, devem despertar interesse, curiosidade e tesão no público. Se do ponto de vista narrativo ou estético, por exemplo, podem ser consideradas maçantes ou repetitivas isso é outra questão - talvez não menos importantes, mas secundárias, de modo que talvez devêssemos considerar mesmo essa repetição como uma espécie de reiteração mimética e incisiva de certa informação que, em alguma medida, não deixa de ser também criativa.

Pensar as relações entre linhas de fluxo e contrafluxos na produção pornográfica significa pensar sua multiplicidade estética, a potência porosa com consegue penetrar através de espaços tão heterogêneos das sociabilidades, bem como os silêncios e sussurros que ainda constituem sua presença enquanto produto e experiência de consumo. Implica pensar as relações que pornô e cinema convencional estabelecem entre si em um momento da história do cinema onde os limites entre representações do sexo dizem respeito mais ao invólucro de sentidos do qual ele está permeado do que propriamente sobre sua plausibilidade. E, em última instância, no contexto do material aqui analisado, implica perceber como a animação em 
seu aspecto representacional conserva aspectos das tensões e desejos da arena coletiva, ao mesmo tempo em que produz inflexões estéticas e técnicas sobre o cinema (pornográfico) convencional.

O mote inicial do trabalho se constituiu em analisar as experiências contemporâneas sobre o erotismo a partir dessa região tríplice de fronteira entre monstruosidade, internet e animação de modo a entrever como a animação pornográfica permite entender ideias relativas às convenções, limites e possibilidades disponíveis para a representação do sexo, de maneira mais restrita, e das interações entre pessoas considerando o modo como a diferença é marcada e erotizada. Assim, o monstro é não apenas um referente imaginário, mas uma metáfora para sinalização de uma gama muito ampla de configurações sociais e de coletividades que se por um lado não podem ser objetivadas na construção dos personagens, por outro não pode ser negada ou ignorada. Mais ainda, pensar essa região tríplice de fronteira exigiu um exercício de considerar como o mundo como um espaço povoado por múltiplas agências, tanto humanas como não humanas. Essas agências assumem um lócus especial na estruturação do pornô tendo em vista que a finalidade última do filme pornográfico, animado ou não, é a excitação através do conteúdo. Assim, imagens, computador e a própria internet atuam em rede como forma de garantir a eficácia desse projeto.

Essa leitura insere a monstruosidade pornográfica em um registro mais amplo, e nos permite refletir, por um lado, sobre o esgotamento de um conjunto de símbolos e significados existentes sobre ele e por outro, sobre a cambialidade das fronteiras entre o normal e o anormal, o sensível e o sensorial. $\mathrm{O}$ enfraquecimento das suas simbologias mais tradicionais, como concretização do que é desconhecido e, portanto, temido e desejado, incorporados em diferentes produtos, pornográficos e não pornográficos, não significa o fim do monstro, mas o 
alargamento e abertura de novos campos criativos. Esses novos espaços de produção, que agora também incluem os usuários/consumidores, se caracterizam pela lógica da montagem, tão comum às obras cinematográficas analógicas e à bricolagem da produção cultural.

Por outro lado, a animação tem se sofisticado e o design das imagens e dos corpos parece cada vez mais incorporar uma estética de verossimilhança entre realidade convencional e realidade animada. Esse aspecto de realismo é um atributo que sugere não apenas a dimensão técnica que justapõem o pornô a animação pornográfica, mas sobremaneira um recurso que possibilita uma maior elasticidade, uma virtualização dos corpos através dos quais encontros entre prodígios corporais e categorias ontológicas que seriam difíceis de serem executadas através de uma realização com atores humanos (e não apenas humanizados, como no caso da animação). É a partir desse recurso que estabelece a possibilidade de olhar dentro do corpo animado, de expandi-lo, fazer falar, gemer, simular dor e gozo, de mover-se e excitar-se, que se desenvolve também uma agência com potencialidades de afetar-excitar. Humanos, máquinas e imagens compartilham assim uma arena de interação mobilizada pela possibilidade de excitação, pelo uso recreativo dos corpos e imaginários através de uma potentia gaudadendi.

No universo da animação pornográfica, a caracterização do monstro é uma caracterização fundamentalmente corporificada. Sua existência é manifesta de maneira material através de atributos que informam o excesso de músculos, de membros, as desmedida, a desproporção de forças quando contratadas com os seres com os quais interage. Contudo, essa mesma existência assustadora é elaborada em um fluxo desejante que canaliza e pornifica a monstruosidade em uma linguagem erótica, em uma narrativa visual marcada por convenções de linguagem onde a violência do encontro, o 
Grotesco desejo: Erotismo, monstruosidade e internet desde a animação pornô

desnível dos corpos (em cor, textura, tamanhos, formas, consistência, aparência) é explorada e amplificada. Essa estética dos exageros que justapõe na mesma cena mulheres e homens brancos, jovens, de corpos atléticos em situação de aparente temor é a mesma que caracteriza os monstros como outra coisa que não isso. Em última instância, isso redunda na produção e reiteração do que chamamos de estruturas narrativas que se caracterizam pela reiteração de três momentos de primordial importância: o encontro, a imobilização e o sexo.

A organização desses momentos na narrativa constrói a interação com o monstro como uma arena sempre conflitual e perigosa, marcada pelo uso da força desproporcional e pela ação de signos e símbolos que remetem ao uso da violência que se equacionam a uma imagem de tesão e excitação. Se por um lado a configuração visual é de estrangulamento, apertos, imobilizações e lágrimas, por outro a configuração sonora mistura gritos, gemidos. Esses mesmos elementos que caracterizam o encontro como uma ameaça iminente, não estão ausentes da pornografia convencional onde atores e atrizes reais encenam cenas e interações marcadas pelo emprego da força e da violência que testam e medem constantemente os limites do erotismo.

\section{Referências bibliográficas}

ABREU, Nuno Cesar. O olhar pornô. A representação do obsceno no cinema e no vídeo. Campinas: Mercado das Letras, 1996.

BARSS, Pathen. Erotic Engine. How pornography has powered mass communication from Gutenberg to Google. s.L.: Anchor Canada, 2010.

COHEN, Karl F. Censorship of Theatrical Animation. In: Forbiden Animation. Censorede Cartoons and Blacklisted 
Animators in America. Jefferson: McFarland \& Company Inc., 2004.

COURTINE, Jean-Jacque. Uma arqueologia da curiosidade. In: Decifrar o corpo. Pensar com Foucault. Petrópolis: Editora Vozes. 2013. (Cap.3)

COURTINE, Jean-Jacque. O corpo inumano. In: CORBIN, Alan; COURTINE, Jean-Jacques; VIGARELLO, Georges. História do Corpo. Da Renascença às Luzes. 4.ed. Petropolis: Vozes, 2010.

CRUZ, Paula Ribeiro da. Do Desenho Animado à Computação Gráfica: A Estética da Animação à Luz das Novas Tecnologias. Monografia de conclusão de curso. Faculdade de Comunicação. Universidade Federal da Bahia, 2006.

DE LA FLOR, Alexandra Flores. La exhibicíon de seres deformes (Monstruous) em España durante la Edad Moderna. In: Revista Sans Solei - Estudios de la Imagen, vol. 7, 2015, pp. 25-44.

DÍAZ-BENITEZ, Maria Elvira. Nas redes do sexo. Os bastidores do pornô brasileiro. Rio de Janeiro: Zahar, 2010.

DOMINGUES, Delmar Galise. $O$ uso de metáforas na computação. Programa de Pós Gradução em Comunicação Comunicação (Mestrado). Universidade de São Paulo, 2001.

DURAN, Gilbert. O imaginário. Ensaio acerca da ciência e da filosofia da imagem. Rio de Janeiro: Difel, 2011.

EL FARR, Alessandra. Páginas de Sensação: literatura popular e pornográfica no Rio de Janeiro (1870-1924). Rio de Janeiro: Companhia das Letras, 2004.

FAUSTO-STERLING, Anne. Sexing the body. Nova York: Basic Books, 2000.

FOUCAULT, Michel. História da Sexualidade. A vontade de saber. 13.ed. Rio de Janeiro: Graal, 1999. Vol. 1.

FOUCAULT, Michel. Os anormais. Curso no Collège de France (1974-1975). São Paulo: Martins Fontes, 2002.

GERACE, Rodrigo. Cinema Explícito. Representações cinematográficas do sexo. São Paulo: Editora Senac, 2016. 
Grotesco desejo: Erotismo, monstruosidade e internet desde a animação pornô

GIL, José. Monstros. Porto: Editora Relógio d'Água, 2006. (Coleção Antropos).

GREGORI, Maria Filomena. Prazeres Perigosos. Erotismo, gênero e limites da sexualidade. São Paulo: Companhia das Letras, 2016.

HARAWAY, Donna. "Saberes Localizados: a questão da ciência para o feminismo e o privilégio da perspectiva parcial". In: Cadernos Pagu, vol. 5. Campinas, 1995. p.07-41.

HUNT, Lyn. A invenção da pornografia: a obscenidade e as origens da modernidade. São Paulo: Hedra, 1999.

KHAR, Brett. As fantasias. In: $O$ sexo e a psique. Rio de Janeiro: Editora Best Seller, 2009. (Parte 3).

LEHA, Julio (org.) Monstros e Monstruosidades na literatura. Belo Horizonte: Editora UFMG, 2007.

LEITE JUNIOR, Jorge Leite. Das maravilhas e prodígios sexuais. A pornografia bizarra como entretenimento. Rio de Janeiro: Annablume, 2006.

LUCENA JUNIOR, Alberto. Arte da Animação: Técnica e estética através da história. 3.ed. São Paulo: Editora Senac, 2001.

MACHADO, Paula Sandrine. O Sexo dos anjos: representações e práticas em torno do gerenciamento sociomédico e cotidiano da intersexualidade. Tese de Doutoramento em Antropologia Social. Porto Alegre: Programa de Pós-graduação em Antropologia Social/Universidade Federal do Rio Grande do Sul, 2008.

MARTIN, Emily. "The eff and the sperm: how science has constructed a romance based on stereotypical male-female roles". In: LASLETT, Barbara; KOHLSTEDT, Sally; LONGINO, Hellen; HAMMONDS, Evelyn, (Eds.). Gender and Scientific authority. Chicago: University of Chicago Press, 1996, p.323339.

OGIEN, Ruwen. Pensar la pornografia. Barcelona: Paidós, 2005. 
PRECIADO, Beatriz (Paul). Texto Yonqui: sexo, drogas y biopolítica. Barcelona: Anagrama, 2010.

PRECIADO, Paul (Beatriz). Manifesto Contrassexual. Barcelona: Editora Anagrama, 2011.

RUBIN, Gayle. “O Tráfico sexual - entrevista com Gayle Rubin". Cadernos Pagu, n. 23. Vol.1. Campinas, 2003

SANTAELLA, Lúcia. Navegar no ciberespaço. $O$ perfil cognitivo do leitor imersivo. São Paulo: Paulus, 2004. (Coleção Comunicação)

SYPER, Juliano. Teoria e Tecnologia. In: Conectado. O que a internet fez com você e que você pode fazer com ela. Rio de Janeiro: Zahar, 2007.

TEIXEIRA, Alexandre Eustáquio. A Fabricação do corpo, a animação do outro: um estudo sobre imagens e representação do monstro na animação pornográfica contemporânea. Tese de Doutoramento em Ciências Sociais. Belo Horizonte: Programa de Pós-Graduação em Ciências Sociais / PUC-Minas, 2017.

WAGNER, Roy. A Invenção da Cultura. São Paulo: Cosac Naify, 2010.

WAGNER, Roy. Habu: innovation and meaning in Daribi religion. Chicago: Chicago University Press, 1972.

WILLIAMS, Linda. "Screeming sex: revelando e dissimulando o sexo". Cadernos Pagu, vol.38, n.1. Campinas: Unicamp, 2012, p. 13-51.

WILLIANS, Linda. Hard Core. power, pleasure, and the frenzy of the visible. Los Angeles: California University Press, 1999.

Enviado em: 15/02/2017

Aceito em: 31/08/2017 